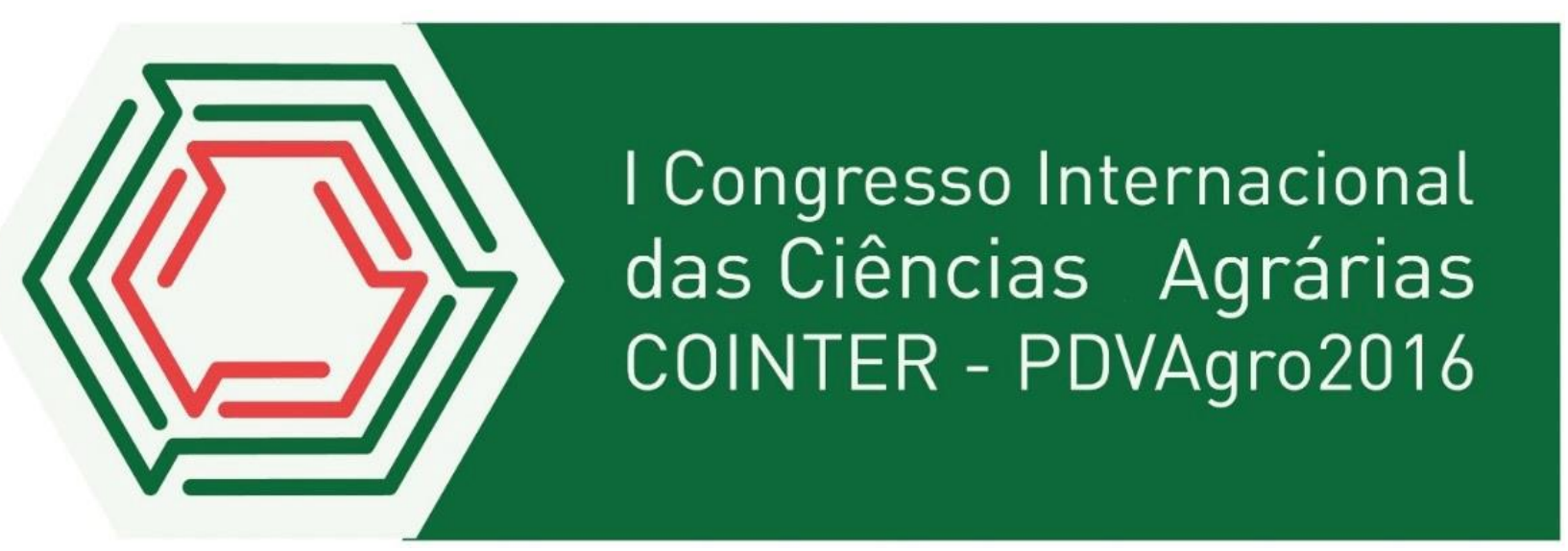

\title{
IMPORTÂNCIA DA EDUCAÇÃO AMBIENTAL NA AGRICULTURA URBANA: ESTUDO DE CASO NA CIDADE DO RECIFE, PERNAMBUCO
}

\author{
Apresentação: Comunicação Oral \\ Fabrício Ângelo Gabriel ${ }^{1}$; Ana Paula Xavier de Gondra Bezerra ${ }^{2}$; Emmanuelle Maria Gonçalves \\ Lorena $^{3}$; Ítala Gabriela Sobral dos Santos ${ }^{4}$
}

\begin{abstract}
Resumo
$\mathrm{Na}$ sociedade atual, a educação ambiental se torna percussora em questões relacionadas a problemas ambientais e a relação harmônica e equilibrada entre homem e meio ambiente. Por sua vez, a agricultura urbana vem se destacando no cenário nacional com o intuito de reforçar o processo de desenvolvimento sustentável. Nesse sentido, o presente trabalho teve como objetivo o levantamento de informações referentes a agricultura urbana e periurbana aliado a questões ambientais na Cidade do Recife, Pernambuco. O trabalho foi realizado no Bairro do Curado com visitas sistemáticas para observação e diagnóstico da área. Questionários semiestruturados foram aplicados a agricultores que praticam a atividade com questões relacionadas a educação ambiental, manejo do solo, utilização de agrotóxicos e técnicas relacionadas ao plantio. Foi constatado que a temática Educação Ambiental não é trabalhada com os agricultores urbanos, visto que foram relatados apenas referentes aos equipamentos de proteção individual que são obtidos por órgão público. No entanto, pouco é o conhecimento quando questionados acerca do uso e ocupação do solo, não possuindo base teórica para o manejo e conservação. Em toda a área de estudo foi observado grande quantidade de resíduos sólidos e deposição irregular de materiais de construção e demolição, além do cultivo ser próximo a passagem de esgoto doméstico e a utilização do método de queimada para limpar a área do cultivo. Desta maneira, vislumbra-se a necessidade de atuação do Poder Público na inserção da educação ambiental nesses locais, principalmente na difusão de conhecimento em relação à segurança alimentar.
\end{abstract}

Palavras-Chave: Cultivo, economia, sustentabilidade, ecologia, desenvolvimento sustentável.

\section{Introdução}

\begin{tabular}{|c|c|c|c|c|c|c|c|}
\hline $\begin{array}{l}1 \quad \text { Mestrando em } \\
\text { fabricio.gabriel@outlook.com }\end{array}$ & Engenharia & Ambiental, & Universidade & Federal & Rural & de & Pernambuco, \\
\hline $\begin{array}{c}2 \\
\text { anapaula.gondra@gmail.com }\end{array}$ & Engenharia & Ambiental, & Universidade & Federal & Rural & de & Pernambuco, \\
\hline $\begin{array}{c}3 \text { Mestranda em } \\
\text { emmanuelle@lorenas.com.br }\end{array}$ & Engenharia & Ambiental, & Universidade & Federal & Rural & de & Pernambuco, \\
\hline $\begin{array}{c}4 \quad \text { Mestranda em } \\
\text { talagsobral@hotmail.com }\end{array}$ & Engenharia & Ambiental, & Universidade & Federal & Rural & de & Pernambuco, \\
\hline
\end{tabular}


Os estudos voltados ao campo ambiental não são recentes, no entanto, apenas em meados do século XX tiveram corpo e se tornaram mais sistemáticos e necessários (SILVA, 2013). Cuperschmid e Tavares (2002) alegam que desde o início da década de 70 os setores políticos, sociais e econômicos começam a se preocuparem com o meio ambiente de forma ininterrupta e progressiva. No entanto, com o crescimento urbano acelerado e a formação de grandes metrópoles aliados ao subdesenvolvimento em geral, tendem alcançar níveis antes nunca imaginado em relação aos problemas ambientais e qualidade de vida (MAZETTO, 2000). A qualidade de vida é afetada em reflexo da degradação que assola os recursos naturais, essa por vez, é consequência do modelo atual econômico e de desenvolvimento que influenciam na qualidade ambiental (COSTA, 2015).

Santos (2013) destaca que a agricultura é uma das atividades mais antigas exercidas pelo homem, no qual se retira alimento e fornece fonte de renda, além de ser uma prática geradora de emprego. Fernandes (2014) define, de forma geral, que "a agricultura é o resultado das atividades de cultivo desenvolvidas por grupos humanos, com aplicação de algum tipo de técnica, sobre um determinado espaço". O autor ainda corrobora que durante um tempo, a agricultura foi organizada de acordo com diferentes segmentos (sociais, econômicos, políticos entre outros), juntando sistemas agrários a espaços específicos diferentes.

Tomando como base Mougeot (2000) o conceito de agricultura urbana ainda é genérico e ainda não foram plenamente desenvolvidos, mas deixa certo que é a agricultura praticada em centros urbanos (dentro ou na periferia), onde há produção de diferentes produtos alimentícios e não alimentícios, além de (re)utilizar recursos e serviços que estão disponíveis na área urbana e, em consequência, disponibiliza novos recursos, produtos e serviços para aquela determina área. Ferreira (2013) expõe que a agricultura urbana e periurbana são realizadas nos mais variados ambientes da cidade, por diversos grupos sociais, o que deixa claro a sua importância da utilização de um método de produção eficaz para esses espaços. A propósito, a agricultura urbana refere-se à integração de elementos que compõem o meio rural com o urbano, apesar de acontecer através de inserção intrínseca ao modo de vida urbana (FERREIRA; CASTILHO, 2016).

A educação ambiental, de fato, é um processo que atribui conhecimento sobre as questões ambientais, é uma disciplina capaz de transmitir uma nova visão sobre o meio ambiente e formar agentes transformadores no que diz respeito à conservação ambiental (NÓBREGA et al., 2015). Do mesmo modo, a Organização das Nações Unidas para a Educação, a Ciência e a Cultura UNESCO (2005, p. 44) destaca que a "Educação Ambiental é uma disciplina bem estabelecida que enfatiza a relação dos homens com o ambiente natural, as formas de conservá-lo, preservá-lo e de administrar seus recursos adequadamente".

Neste contexto, o presente trabalho teve por finalidade analisar a importância da educação 
ambiental na cooperação de práticas nos cultivos oriundos da agricultura urbana no bairro do Curado na cidade do Recife, Pernambuco.

\section{Fundamentação Teórica}

Segundo Fracalanza et al. (2005) diante da sociedade atual e, principalmente nos países em desenvolvimento, com o aumento da globalização e outros fatores, os serviços básicos estão sendo ineficazes por não acompanharem as demandas e o crescimento da população. Por outro lado, problemas observados hoje podem ter se originados pelo desenvolvimento e protótipo de vida acumulado, são o que mostram os estudos relacionados com o futuro da sociedade quanto ao aspecto de vários campos, dentre eles o ambiental (SANTOS, 2013).

A natureza sempre foi explorada para suprir a necessidade do ser humano, isso para possibilitar o conforto, alimentação, desenvolvimento entre outros benefícios (PERNA, 2013).

De acordo com Ruscheinsky e Vargas (2012), a educação ambiental traz consigo a sensibilização sobre a percepção de elementos formadores da vida cotidiana (terra, água, ar, entre outros) frequentemente ocultos nas referências ao ambiente. Possui dentre suas características a identificação, pelo ser humano, de sintomas e das causas reais que provocam danos ambientais, além de fortalecer o desenvolvimento por práticas que buscam soluções efetivas e adequadas (BRITO et al., 2016).

Silva (2013) expressa que a atividade produtiva, no caso da agricultura, é mais evidente na relação entre homem e meio ambiente, logo, é possível visualizar a transformação realizada pelo trabalho humano no meio e como este último está sendo influenciando. Neste aspecto, cabe a educação ambiental inserir novos conhecimentos em relação a integração do ser humano com o meio ambiente, o que se condiz com o advento de novos conhecimentos, atitudes e valores para a mudança da atual situação ambiental em que nos encontramos (GUIMARÃES, 2005). A educação ambiental pode despertar diferentes perspectivas e valores em comunidades sobre conceitos dos recursos naturais que não existiam antes da utilização de técnicas de sensibilização.

Do ponto de vista de Rodrigues et al. (2015), a prática conservacionista se torna promissora quando se trata do manejo de produtos agrícolas e da estabilidade dos solos, e controle de processos erosivos na agricultura familiar, de modo que a administração incorreta do solo, por exemplo, pode impactar na qualidade e quantidade dos produtos advindos da prática agrícola.

Neste contexto, a questão de desenvolvimento sustentável vem se destacando e orientando pesquisadores quanto ao incremento de novas normas e que levam a grandes discussões, caracterizando o desenvolvimento para questões relacionadas à sustentabilidade e ao meio ambiente (SANTOS, 2013). De certo, poucos são os estudos voltados para este tipo de agricultura, o que se 
torna difícil a formulação e aplicação de políticas públicas específicas para a agricultura urbana e periurbana (ARRUDA, 2006). Neste contexto, se torna fundamental a inserção da educação ambiental na perspectiva de incrementar a essência do desenvolvimento sustentável no objetivo da agricultura urbana.

\section{Metodologia}

A presente pesquisa tem por natureza qualitativa, e baseou-se principalmente em uma análise exploratória, caracterizando, assim, um estudo de caso.

\section{1. Área de Estudo}

A área em estudo tem cerca de 42 ha delimitados pelas alças viárias de interseção entre a BR-232 e a BR-101 (figura 1), próxima a Centro de Abastecimento e Logística de Pernambuco (CEASA), localizado no bairro do Curado, Recife, PE.

Figura 1: Delimitação da área de estudo - Locais de agricultura urbana. Fonte: Adaptada do Google Earth.

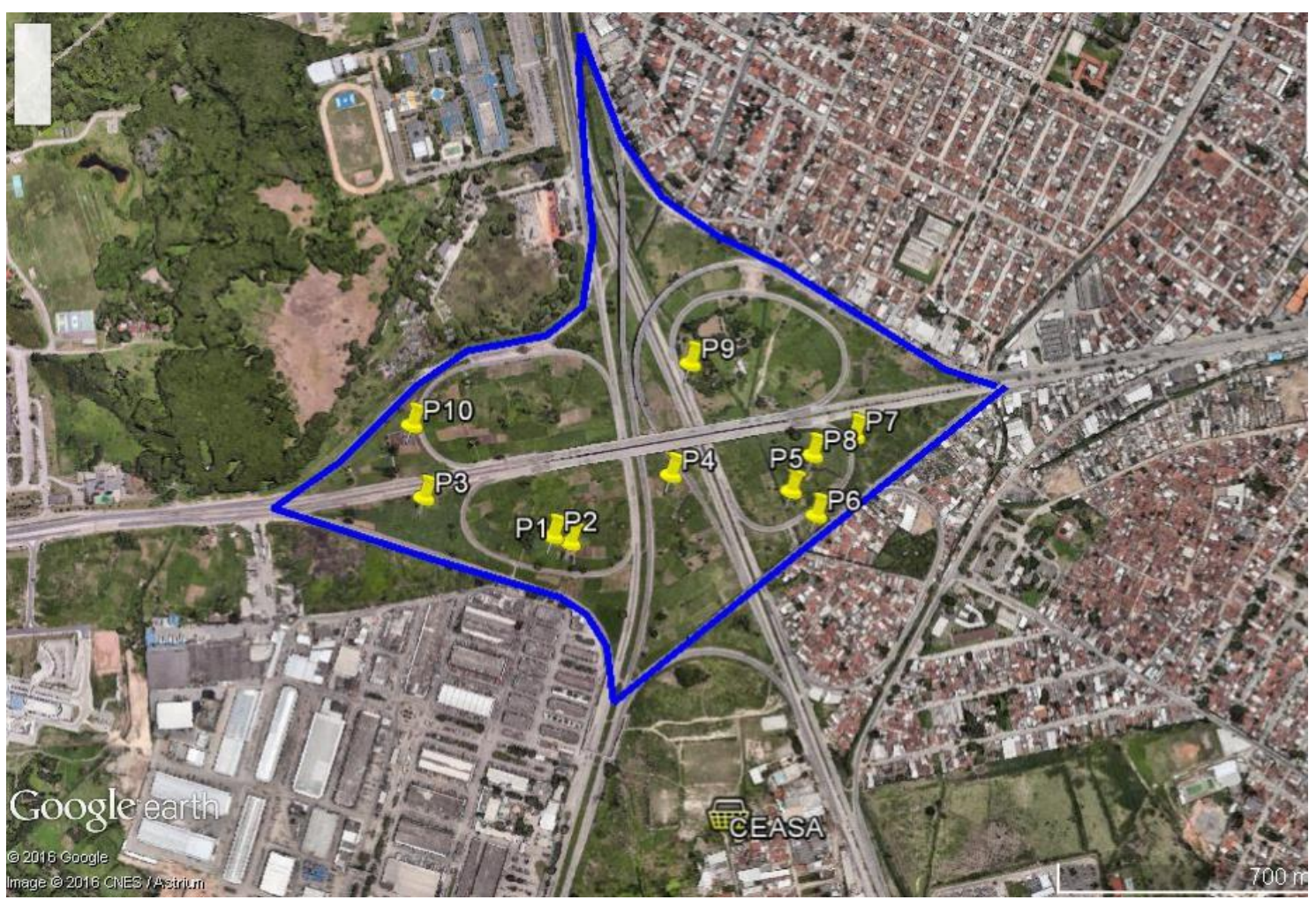

\section{Coleta dos Dados}


Para coleta dos dados foram delimitados 10 pontos os quais foram realizadas visitas técnicas e utilização de métodos de observação das áreas cultivadas, utilizando registros fotográficos e a fotografia georrefenciada pelo Google Earth Pro (Figura 2).

Tabela 1: Delimitação dos pontos de estudo para a realização da visita técnica. Fonte: Adaptada do Google Earth.

\begin{tabular}{|c|c|c|}
\hline Ponto & Latitude & Longitude \\
\hline P1 & $8^{\circ} 4^{\prime} 8.04 " \mathrm{~S}$ & $34^{\circ} 56^{\prime} 37.13^{\prime \prime} \mathrm{O}$ \\
\hline P2 & $8^{\circ} 4^{\prime} 7.91 " \mathrm{~S}$ & $34^{\circ} 56^{\prime} 38.09^{\prime \prime} \mathrm{O}$ \\
\hline P3 & $8^{\circ} 4^{\prime} 7.41^{\prime \prime S}$ & $34^{\circ} 56^{\prime} 45.04^{\prime \prime} \mathrm{O}$ \\
\hline P4 & $8^{\circ} 4^{\prime} 3.50 " \mathrm{~S}$ & $34^{\circ} 56^{\prime} 32.81^{\prime \prime} \mathrm{O}$ \\
\hline P5 & $8^{\circ} 4^{\prime} 2.95 " \mathrm{~S}$ & $34^{\circ} 56^{\prime} 26.55^{\prime \prime} \mathrm{O}$ \\
\hline P6 & $8^{\circ} 4^{\prime} 3.89 " \mathrm{~S}$ & $34^{\circ} 56^{\prime} 25.00^{\prime \prime} \mathrm{O}$ \\
\hline P7 & $8^{\circ} 3^{\prime} 59.48^{\prime \prime} \mathrm{S}$ & $34^{\circ} 56^{\prime} 23.99^{\prime \prime} \mathrm{O}$ \\
\hline P8 & $8^{\circ} 4^{\prime} 0.91 " \mathrm{~S}$ & $34^{\circ} 56^{\prime} 25.88^{\prime \prime} \mathrm{O}$ \\
\hline P9 & $8^{\circ} 3^{\prime} 57.68^{\prime \prime} \mathrm{S}$ & $34^{\circ} 56^{\prime} 33.10^{\prime \prime} \mathrm{O}$ \\
\hline P10 & $8^{\circ} 4^{\prime} 3.91 " \mathrm{~S}$ & $34^{\circ} 56^{\prime} 46.48^{\prime \prime} \mathrm{O}$ \\
\hline
\end{tabular}

Também se utilizou de um questionário semiestruturado aplicado in loco como instrumento de pesquisa. A composição dos questionários se baseou em cinco perguntas abertas que foram aplicadas com três agricultores e donos dos lotes. Os questionários foram compostos por perguntas relacionadas com os seguintes temas:

- Realização de palestras ou cursos para capacitação;

- Técnicas de cultivo;

- Tipo de cultura produzida;

- Origem da água para abastecimento;

- Utilização de agrotóxico.

\section{Resultados e Discussão}

Com a aplicação dos questionários, não foi possível quantificar os demais agricultores responsáveis da área devido à falta dos mesmos no local, não se caracterizando uma amostra significativa para análise estatística, tendo como resultado três respostas que foram avaliadas de 
forma qualitativa. O que foi extraído desses, afirmaram que a Ceasa possui um cadastro e realiza um acompanhamento com os agricultores dos locais escolhidos como foco de estudo. Porém, não foi observado no site da Ceasa nenhum cadastro desses agricultores que esteja disponível para público.

Quando questionados se o órgão responsável fornecia capacitação ou treinamento para utilização de técnicas mais sustentáveis, afirmaram que as técnicas agrícolas utilizadas são passadas de geração a geração, ou seja, não possuindo base teórica para o manejo e conservação.

A educação ambiental, conforme Gama e Mello (2015), promove a possibilidade de melhoria na relação existente entre meio ambiente, homem e terra, de modo que é necessário construir um novo entendimento a contar da ferramenta escolhida de acordo com a opinião de cada membro que compõe o grupo.

Para o uso e ocupação do solo, os agricultores utilizam o método de queimada para limpar a área do cultivo (Figura 3). Esta técnica, de acordo com Rodrigues (2014), é utilizada desde a era primitiva da humanidade, pois facilita o trabalho do agricultor e possui alguns benefícios momentaneamente. $\mathrm{O}$ autor ainda sistematiza que os problemas podem vir de médio e longo prazo, trazendo prejuízos tanto para o meio ambiente quanto para a população circunvizinha. Ferreira e Castilho (2016) destacam a importância da questão ambiental na agricultura urbana, de modo que os agricultores podem usufruir de novas tecnologias, biotecnologia; além da reutilização da água para a atividade e aproveitamento de resíduos sólidos orgânicos.

Por outro lado, tem-se a educação ambiental como um intuito de promoção da percepção em defesa do meio ambiente, o que corrobora em maior relação com o meio em que vivem e facilita garantir com o crescimento econômico e, sucessivamente, a qualidade de vida (PERNA, 2013).

Quando interrogados sobre a utilização de agrotóxicos e o descarte de suas embalagens, os proprietários responderam que não utilizam e que órgão sempre fiscaliza esse item. Isso foi verificado com a observação do local onde não foi encontrada nenhuma embalagem de agrotóxicos, porém foram encontrados embalagens de tinta (Figura 4), o que demostra que nesses locais não possui um armazenamento adequado para resíduos.

Figura 2: A - Formas de tratamento do solo para receber o cultivo- P3; B - Resíduos depositados irregularmente contendo embalagens de tintas -P2. Fonte: Própria. 

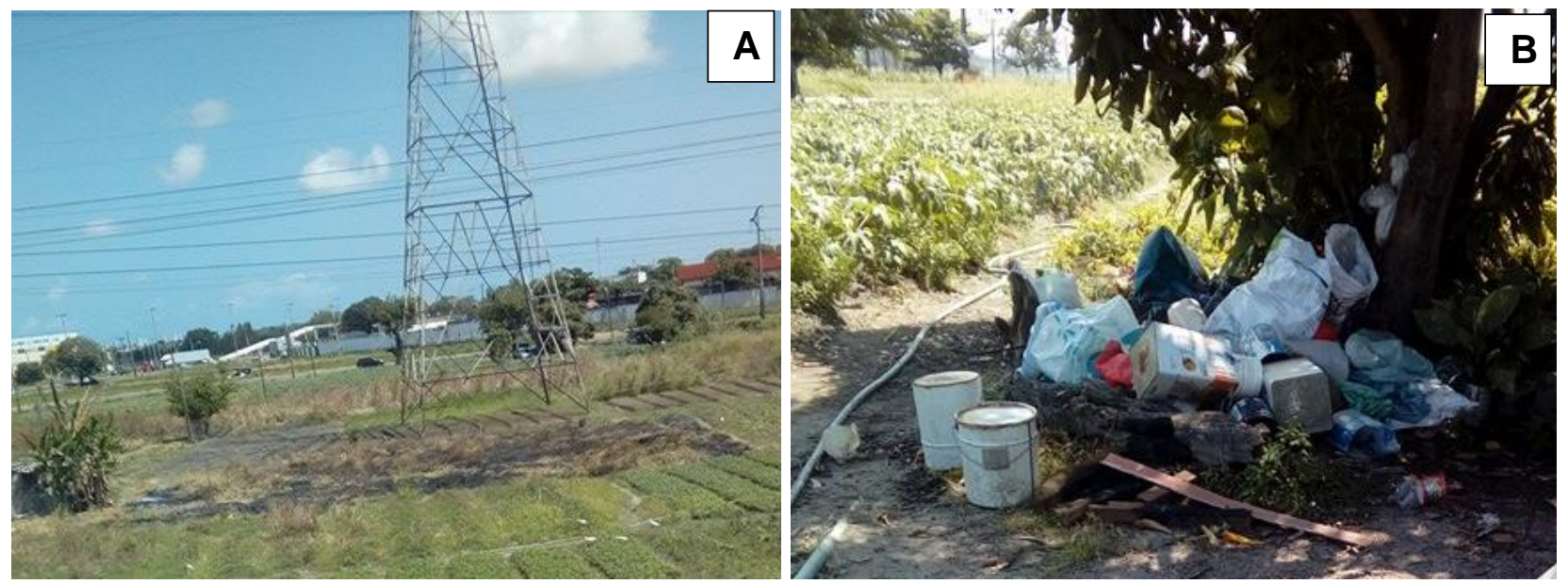

Com relação à utilização do uso de EPI's, afirmaram que o órgão responsável fornece equipamentos de segurança.

Os agricultores afirmaram, ainda, que recebem adubo proveniente da compostagem da Ceasa e os restos de podas de árvores e capim do Caxangá Golf \& Country Clube que são utilizados nos processos do cultivo da cultura. Assim, eles utilizam apenas calcário e adubo orgânico como fertilizantes do solo.

Foi verificado que nesses locais são cultivados três tipos de culturas diferentes, sendo elas: quiabo, coentro e alface, porém são plantadas em períodos diferentes. No período da pesquisa, a cultura foi de quiabo (Figura 5)

Foi também questionado como é realizada a captação de água, e todos afirmaram que vêm do solo, ou seja, através de poço artesiano. O que pode verificar no local é que existe uma caixa para armazenamento de água que não está vedada de maneira adequada, podendo ocasionar proliferação de vetores, o que pode trazer malefícios para a população que reside próximo a essa área (Figura 6). Na área de estudo foi observado grande quantidade de resíduos sólidos e deposição irregular de materiais de construção e demolição, além do cultivo estar localizado próximo a um canal de esgoto doméstico (Figura 7, 8 e 9).

Figura 3: A - Caixa d'água localizada no Ponto P1; B - Cultura do quiabo no Ponto P4 e C -

Deposição irregular de resíduos de construção e demolição - Ponto P7. Fonte: Própria 


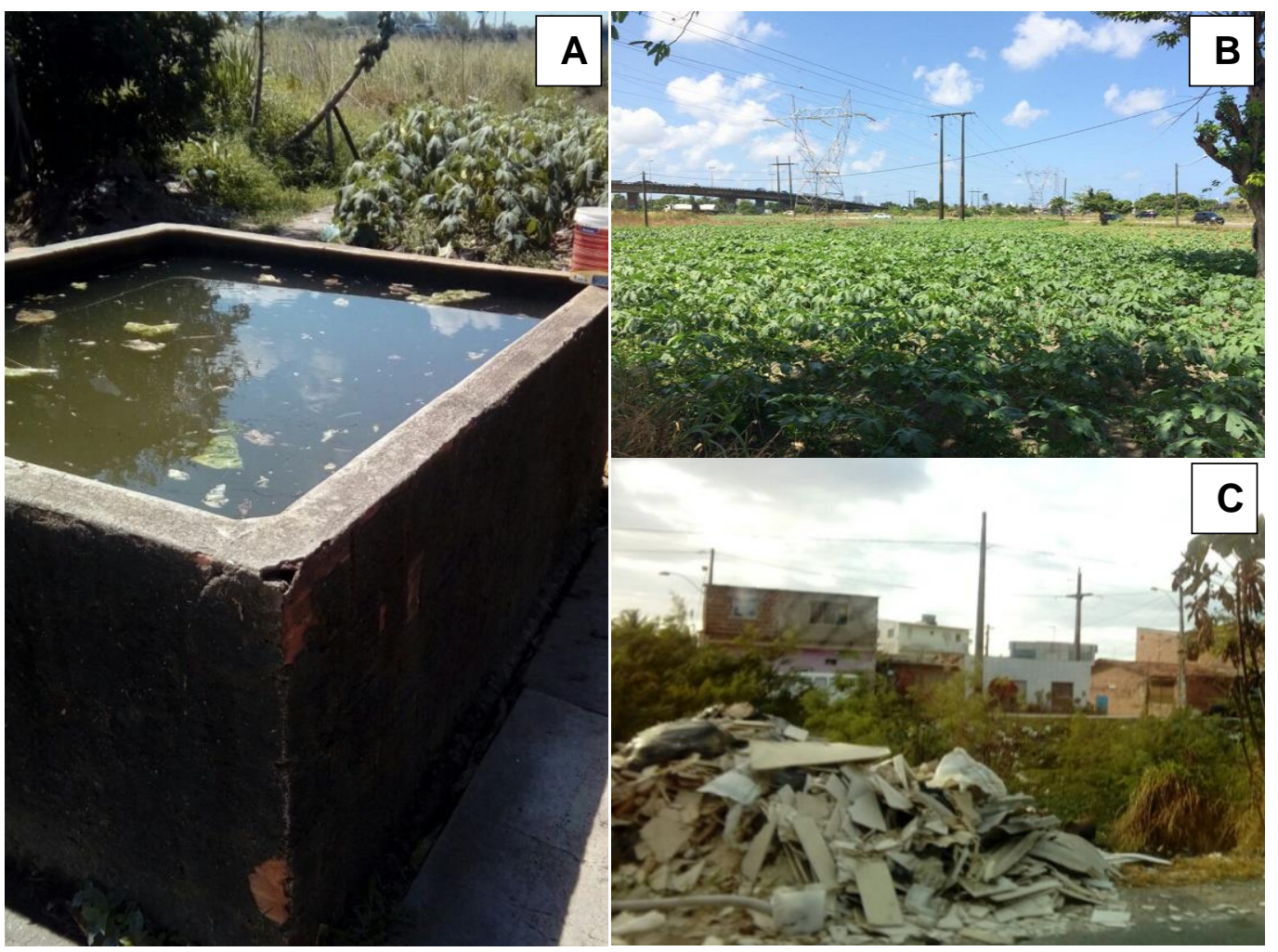

Figura 4: A - Disposição irregular de resíduos sólidos - Ponto P6; B - Canal localizado próximo ao cultivo no Ponto P5. Fonte: Própria.
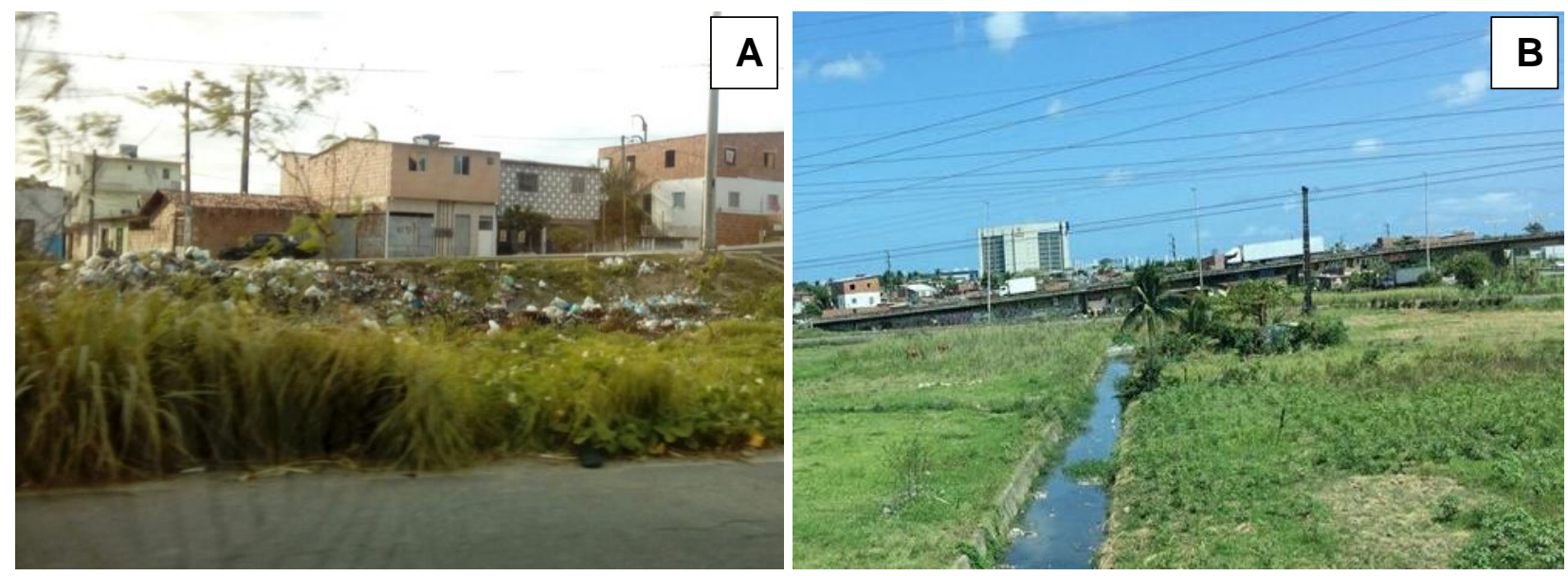

Ferreira (2013) põe explicito que os agricultores urbanos na Cidade do Recife que utilizam às margens de rodovias para cultivar hortaliças, além de não estarem com apoio institucional, possuem conflito e tensão diretamente com os proprietários dos lotes ocupados.

Os pontos P8, P9, P10 encontram se na mesma realidade do que esta disposta nas figuras (3C e 4-A). Podendo observar que devido a proximidade desta área da cidade, sua área de plantio é bastante influenciada por fatores externos, tais como: resíduos urbanos, resíduos de construção 
civil, esgotos, gases liberados pelos veículos, partículas de pneus entre outros. Esses fatores podem comprometer a qualidade de seus produtos, no entanto, observa-se que isso não é levado em consideração pelos agricultores desses locais.

Diante da situação atual, o uso do solo sem o manejo adequado potencializa a contaminação e causa interferência tanto no ambiente local quanto global, essa problemática está ligada diretamente a utilização para atividades agrícolas, industrial e pecuária (PERNA, 2013).

É necessária a atuação do estado como difusor da educação, na preparação do indivíduo em relação a boas práticas de manejo e conservação.

"O Estado é concebido como "educador" na medida em que uma das suas funções mais importantes (e quase sempre esquecida) é elevar a grande massa da população a um determinado nível cultural e moral, nível que corresponde às necessidades de desenvolvimento das forças produtivas e, portanto, aos interesses da classe que está no domínio" (ACCIOLY; LOUREIRO, 2013).

\section{Conclusões}

Pode-se observar que as questões ambientais não foram inseridas na agricultura urbana no local de estudo demostrando uma carência por parte dos órgãos públicos responsáveis por esse grupo.

Com tudo, conclui-se que os problemas urbanos, tais como, lixo urbano, ocupação irregular, emissão de poluentes e educação da comunidade afetam diretamente no produto local, e os agricultores não têm o conhecimento da gravidade que problemas como esses podem influenciar na qualidade de vida dos consumidores.

Conclui-se que a educação ambiental não é aplicada nesse local e que a inserção de metodologias para sensibilizar os agricultores e a população poderá resultar em ações que propiciem condições de vida digna no meio rural, conservação ambiental e sustentabilidade do produto e do local.

\section{Referências}

ACCIOLY, I. B.; LOUREIRO, C. F. B. Análise crítica do programa de educação ambiental e agricultura familiar do ministério do meio ambiente. In: VII Encontro de Pesquisa em Educação Ambiental, 2013, Rio Claro - SP. Anais do VII Encontro de Pesquisa em Educação Ambiental, 2013. 
ARRUDA, J. Agricultura urbana e periurbana em Campinas/SP: análise do Programa de Hortas Comunitárias como subsídio para políticas públicas. Campinas, 2006. 147 p. Dissertação (Engenharia Agrícola). Faculdade de Engenharia Agrícola, Unicamp, 2006.

BRITO, V. L. T.; MORAES, L. A.; MACHADO, R. R. B.; ARAÚJO, M. F. V. Importância da educação ambiental e meio ambiente na escola: uma percepção da realidade na Escola Municipal Comendador Cortez em Parnaíba (PI). Revbea, São Paulo, v. 11, n. 2, p. 22-42, 2016.

COSTA, C. A. G. Horta subsídios para desenvolvimento da educação ambiental na escola: um estudo de caso no Ensino Médio no município de Gurjão. Rev. Dig. Secr. Est. Educ. da Paraíba, 2015.

CUPERSCHMID, N. R. M.; TAVARES, M. C. Atitudes em relação ao meio ambiente e sua influência no processo de compra de alimentos. Revista Interdisciplinar de Marketing, v. 1, n. 3, p. 5-14, 2002.

FERNANDES, S. Diagnóstico socioeconômico e ambiental de sistemas agrários: um estudo sobre a agricultura familiar camponesa no distrito de Santa Teresinha - Palmeira das Missões/RS. Pelotas, 2014. 161 p. Dissertação (Geografia). Instituto de Ciências Humanas, UFPel, 2014.

FERREIRA, R. J. Agricultura urbana e periurbana e políticas públicas: contribuição à discussão do tema a partir de uma análise espacial em Recife e Vitória de Santo Antão/PE. Recife, 2013. 231 p. Tese (Geografia). Centro de Filosofia e Ciências Humanas, UFPE, 2013.

FERREIRA, R. J.; CASTILHO, C. J. M. Agricultura urbana e gestão territorial em Recife/PE/Brasil: qual o lugar da agricultura urbana no planejamento da cidade? Ateliê Geográfico, Goiânia, v. 10, n. 2, p. 65-81, 2016.

FRACALANZA, H.; AMARAL, I. A.; MEGID NETO, J.; EBERLIN, T. S. A educação ambiental no Brasil: panorama inicial da produção acadêmica In: V Encontro Nacional de Pesquisa em Educação em Ciências, 2005, Bauru - SP. Anais do V Encontro Nacional de Pesquisa em Educação em Ciências, 2005.

GAMA, A. A. F.; MELLO, A. H. Educação ambiental em assentamentos rurais: uma tecnologia social para conservação socioambiental e geração de renda. Rev. Eletr. Em Gestão, Educ. e Tecnol. Ambiental. Santa Maria, v. 19, n. 2, p. 1105-1109, 2015.

MOUGEOT, L. J. A. Agricultura Urbana: Conceito e Definição. International Development Research Centre (IDRC). Revista de Agricultura Urbana, nº 05, 2000.

MAZETTO, F. A. P. Qualidade de vida, qualidade ambiental e meio ambiente urbano: breve comparação de conceitos. Sociedade \& Natureza, Uberlândia, v.12, n²4, p. 21-31, 2000.

NÓBREGA, E. P.; SARMENTO, M. I. A.; OLIVEIRA, P. R. R.; HAFLE, O. M. Educação ambiental nas séries iniciais da Escola Municipal de Ensino Fundamental João Lopes da Silva Município de São Francisco, Paraíba. Cadernos de Ecologia, v. 10, n. 3, 2015.

PERNA, D. Educação ambiental e a química no curso de técnico em agricultura do Instituto Federal de Mato Grosso - Campus Cáceres - MT. Seropédica, 2013. 65 p. Dissertação (Educação Agrícola). Instituto de Agronomia, UFRRJ, 2013. 
RODRIGUES, M. F. Adoção do uso do fogo na agricultura: uma análise das crenças dos assentamento e produtores das regiões do DF e entorno. Brasília, 2014. 71 p. Relatório (Gestão do Agronegócio). Faculdade UnB de Planaltina, UnB, 2014.

RODRIGUES, R. F.; LIMA, P. M. L.; LIMA, A. M.; MASUTTI, C. S. M. Agricultura familiar no município de Jaguarari, Bahia: conservação de nascentes e expansão das ações ambientais por integração de saberes "etno" e acadêmico. Extramuros, v. 3, n. 1, Ed. Esp., 2015.

RUSCHEINSKY, A.; VARGAS, S. H. N. de. Agroecologia e reforma agrária: integração possível, educação necessária. In: RUSCHEINSKY, A. (Org.). Educação Ambiental: abordagens múltiplas. 2. ed. Porto Alegre: Penso, p. 161-186, 2012.

SANTOS, E. J. Educação ambiental e agricultura familiar: uma análise do povoado de Lagoa das Flores em Vitória da Conquista, BA. Medianeira, 2013. 44 p. Monografia (Especialização em Gestão Ambiental de Municípios), Campus Medianeira, UTFPR, 2013.

SILVA, M. F. S. Limites e contribuições da educação ambiental e da agricultura de base agroecológica no Extremo Sul do Brasil: o projeto de agricultura urbana e periurbana em Rio Grande e São José do Norte (RS). Rio Grande, 2013. 210 p. Tese (Educação Ambiental). FURG, 2013.

UNESCO. Década da Educação das Nações Unidas para um Desenvolvimento Sustentável, 